\title{
Factors influencing choice of strategic management modes of small enterprises
}

\author{
Nyangara Asaka Charles ${ }^{1 *}$, Patrick B Ojera ${ }^{2}$ and Oima David ${ }^{3}$
}

\author{
* Correspondence: \\ nchali06@yahoo.com \\ ${ }^{1}$ Department of Project Planning \\ and Management, School of \\ Business Management and Public \\ Administration, Amoud University, \\ Borama, Somaliland \\ Full list of author information is \\ available at the end of the article
}

\begin{abstract}
Studies indicate that $75 \%$ of small enterprises in the world fail during their first 5 years of operation. In Kenya, just about 20\% grow to the next size category. Scholars have prescribed formal strategic management modes, but the small enterprises (SEs) continue to not only fail but also depict informal strategic management modes. However, few studies have been done to examine whether the dismal performance of SES is due to other factors unrelated to the management of the enterprises, especially in the context of a developing country like Kenya. The specific objectives were to identify the strategic management modes employed by the small enterprises in Kisumu County with specific reference to the Youth Enterprise Fund beneficiaries in Kisumu County and to assess the factors influencing the choice of these modes. The study was anchored on Mintzbergs' theories on deliberate, emergent, and reactive strategic management modes. The study adopted a descriptive cross-sectional research design. The target population was the 242 small enterprises run by the Youth Enterprise Development Fund (YEDF), out of which 134 enterprises were sampled using Yamane's criteria. The study adopted questionnaire and interview methods as the basic data collection methods with the questionnaire being tested through content validity index and Cronbach alpha's internal consistency index, respectively. The study found that the basic modes used by small enterprise were deliberate, emergent, and reactive and that the small enterprises in Kisumu County used these modes interchangeably but relied more on the reactive mode of strategic management. The study revealed that the choice of these modes was dictated by the personal, environmental, and firm characteristics of the enterprises. The study concludes that continued exposure to formal modes would only sustain the endemic failure of the SEs because the SEs need formal exposure to models that address their situation. The study therefore urgently recommends formalization of elements of reactive strategic management modes and the personal factors in small firm curricula.
\end{abstract}

Keywords: Informal strategic management; Deliberate strategic management mode; Emergent strategic management; Reactive strategic management

\section{Background}

The concept of strategic management is viewed differently by scholars of small enterprises. Indeed, an increasing amount has been written on strategic management for small enterprises (SEs), and a number of modes of strategic management have been proposed. Each of these modes, however, is unique in terms of its composition, logic, and emphasis, and there seems to be no consensus on how strategic management

(c) 2015 Charles et al.; licensee Springer. This is an Open Access article distributed under the terms of the Creative Commons Attribution License (http://creativecommons.org/licenses/by/4.0), which permits unrestricted use, distribution, and reproduction in any medium, provided the original work is properly credited. 
should be conducted or on whether a given plan is suitable for every small business (Hill and Gareth 2012a). Two contentious modes prevail: the formal strategic management modes and the informal strategic management modes.

Formal strategic management modes conform to the conventional wisdom that the strategic management modes that managers use, the patterns in actions they develop, the positions and postures they establish, and therefore the performance levels they achieve must all flow from prescribed models (Menzel and Günther 2012; Ansoff 1965; Hofer and Schendel 1978; Porter 1985, and more recently, Pearce and Robinson 2011). Some schools of thought, however, have viewed strategic management as an informal, unstructured, and instinctive decision-making course that does not bear the rational analytical systems of the classical approaches espoused to the small enterprises by classical theorists (Carson 1990; Minzberg 1978, 2001; Quinn 1980; Verreynne 2006).

The informality in the management of small enterprises has been the main contention floated by classical strategic management proponents for their underperformance (Thompson, Gamble, and Strickland), but as Mintzberg and Waters (1985) and Gibbons and O'Connor (2005) observe, strategies form very differently from those assumed by prescriptive models espoused by classical theorists and that strategies can be emergent. Hill and Gareth (2012b) have called for a new paradigm that recognizes the non-equilibrium nature of small-scale enterprises. According to Hill and Gareth (2008), small firms seldom have the economic or political power to control their environment. They have to be flexible and adjust to changes in the resource situation of their environment.

Small enterprises are the key engines of employment, alleviating poverty and improving equality (Gomez 2008). SEs, by number, dominate the world business stage. More than $95 \%$ of enterprises across the world are SEs, accounting for approximately $60 \%$ of private sector employment (BIS 2012; Zainol and Ayadurai 2011; Huang 2011). In the year 2012, the small enterprise sector created up to $80 \%$ of the total employment and contributed between 18\% and 20\% to the GDP in Kenya (Government of Kenya 2012). However, the SEs are characterized by high failure rates (G.O.K. 2003). Other than their high failure rates, the majority of the SEs are also not growth prone as most start small and remain small (Mead 1994, 1999; De la Viña et al. 2005). Further, according to Pearce and Robinson (2011), small enterprise operations are still predominantly a local or a regional market rather than a national or international market, and they tend to have a very limited share of a given market. The equity of small firms is generally owned by one person or, at most, a very few people whose management style is greatly personalized. Besides, the small businesses face external environmental forces that are beyond their control. These forces come in the form of political, economic, social, technological, environmental, and legal factors and can rarely be influenced by management decisions since they are external to the company (Morrison 2006). Further, Sarwoko et al. (2013) found that performance of small business is to be determined by the characteristics of the owner/manager. Wang and Walker (2012) postulate that ownership motivations are central to understanding the planning practices in small- and medium-sized enterprises (SMEs). They found that levels of strategic planning are higher in SMEs which have owner-managers who are growth oriented and lower in those which have owner-managers who pursue non-economic personal agendas.

These empirical findings make it imperative that any study on informal strategic management take cognizance of the role other factors play in moderating the effect of informal 
strategic management on performance of the small enterprises. To this end, this study queried whether the performance of the small enterprises could be attributed to factors not related to strategic management of these firms. While the empirical studies have delineated factors that affect small enterprise performance, no study has attempted to find out which of the factors dictate the particular informal strategic management mode a small enterprise owner would choose in order to leverage the performance of his/her enterprise. This study therefore attempted to examine which of these factors determine the strategic management posture a small enterprise takes in pursuit of better performance with specific reference to the Youth Enterprise Fund in Kisumu County. Kisumu County is one of the 47 counties in Kenya. It is located in the western side of Kenya. The county was chosen because it typifies the other counties in Kenya in terms of Youth Enterprise Development Fund (YEDF) administration. It is also endowed with a myriad of business opportunities ranging from agricultural to small-scale commercial activities. However, these activities have not yielded much benefit to the communities in the county.

The government of Kenya established the YEDF in June 2006 as one of the strategies of addressing youth unemployment. The fund is one of the flagship projects of Vision 2030, under the social pillar. The fund is a strategy of gainfully engaging the youth, a majority of whom are unemployed (Republic of Kenya 2007). This vision is to be achieved through provision of credit and equipping the youth with appropriate skills to creatively engage in economically viable activities (Youth Enterprise Development Fund 2012). Besides ensuring that the youth have adequate business skills, YEDF also assists the youth in identifying and tapping into business opportunities while embracing modern business management techniques. To date, the fund has provided entrepreneurship training to over 200,000 youths and supported two national business plan competitions in which over 10,000 youth entrepreneurs have been trained and winners awarded. However, according to Amenya et al. (2011), a majority of groups still find it difficult to repay their loans. Besides, the YEDF is yet to make an impact in society. This is despite the famed management training and provision of funds to the small businesses. The Youth Enterprise Development Fund was therefore a critical case because the beneficiaries had been offered the conditions recommended by small enterprise scholars and practitioners for success, namely strategic management training and finance (Karlan and Valdivia 2011), yet, according to Amenya et al. (2011), the YEDF was yet to make an impact in society despite the strategic management training and provision of funds. But with a largely unstructured operational environment, it is not clear which strategic management modes small enterprises in Kisumu County employ nor are the factors that influence them to choose a particular strategic management mode obvious.

The main research questions were as follows:

1. What are the major strategic management modes employed by small enterprises in Kisumu County?

2. What factors influence the choice of the particular strategic management modes adopted by small enterprises in Kisumu County?

\section{Conceptual framework}

Guided by the theory of deliberate, emergent, and reactive strategies of Mintzberg and Waters (1985), the study will be modeled on the figure below. 
The figure depicts the dependent variable as the informal strategic management mode. Three informal strategic management modes are pertinent in business management literature: emergent, reactive, and deliberate (Mintzberg et al. 1998). According to Mintzberg and Waters (1985), emergent strategies are strategies which appear without preconception, since many small enterprises tend to focus on daily operations or operational activities, with strategies emerging from practice. However, in the face of a turbulent business environment or crisis, the SE manager can employ a reactive mode of decision-making and implementation. A reactive strategy making and management mode involves unplanned actions by management due to pressures from the environment that are later adopted as strategies if the actions were found to work towards the achievement of the goal. Nevertheless, the SE manager will often come up with short-term deliberate strategies in the course of managing the small business. In this study, deliberate, emergent, and reactive strategies are conceptualized as the combination of informal strategies that may be viewed as organizational when they are modeled together as patterns to improve the performance of the enterprise. Further, deliberate strategies are measured by the presence of formal written down plans and strict adherence to those plans, while the emergent strategies are measured by absence of formal plans and reliance on learning from past experiences. The reactive strategies are measured by both absence of formal plans and reliance on instincts as strategic issues arise.

In small enterprises, successful strategy formulation and implementation is related to the firm factors, the owner's personal factors, and the external environment in which the small enterprise operates (Menzel and Günther 2012). In this study, firm characteristics are measured by scope of operations in terms of markets served - local, regional, or international; scale of operations in terms of production or operational capacity; ownership structure in terms of decision-making system; and size in terms of small number of employees. The Personal Entrepreneurial Competency (PEC) test is used to measure the owner's personal factors. The test contains ten questions that have been found to measure the competency of an entrepreneur. The macro-environment is measured using the political, economic, sociocultural, technological, and ecological factors (PESTE model). These are the independent variables that, if taken cared of, would lead to correct choice of a strategy for this relationship (Figure 1).

\begin{tabular}{|c|c|}
\hline Independent Variable & Dependent Variable \\
\hline $\begin{array}{l}\text { - Firm Characteristics } \\
\text { - Scope of Operation } \\
\text { - Scale of Operation } \\
\text { - Ownership Structure } \\
\text { - Size } \\
\text { - Personal characteristics } \\
\text { - PEC } \\
\text { - External Environmental factors } \\
\text { - Political } \\
\text { - Economic } \\
\text { - Socio-cultural }\end{array}$ & $\begin{array}{l}\begin{array}{l}\text { Informal Strategic management } \\
\text { Modes }\end{array} \\
\text { Deliberate } \\
\begin{array}{l}\text { Availability of Formal } \\
\text { Plans }\end{array} \\
\qquad \text { Strict Adherence to Plans } \\
\text { Emergent } \\
\text { - Absence of Formal Plans } \\
\text { - Experience and Learning } \\
\text { Reactive }\end{array}$ \\
\hline
\end{tabular}

Figure 1 Conceptual framework on the interaction between informal strategic management modes of SEs and performance. Adapted from Menzel and Günther (2012). 


\section{Review of studies relating to informal strategic management}

There are different studies undertaken on what mode the strategic management process should take. While deliberate (rational) strategic management modes in which analysis and extensive access to information play a pivotal role have long been viewed as the central premise of strategic management theory, their importance to small firms is now being questioned (Lumpkin and Dess 2006). The critics argue that traditional perspectives present an idealistic view of the strategy-making process, far removed from the practical and realistic side of day-to-day management of organizations (Gibbons and O'Connor 2005). Nagel (1984) stated that small organizations are less likely to utilize conventional strategic management models and strategic planning concepts than large organizations. Gibb and Scott (1985) also found an absence of formal strategic management in small businesses for the organization, in the large company planning sense. In a survey of small engineering firms in Bangladesh, A. A. Moyeen, Unpublished Work found the reasons for lack of formal strategic management as follows: (1) small business leaders are often more focused on day-to-day operations as opposed to management models and strategic management systems; (2) small businesses have less money to spend on training; and (3) their competitors generally operate the way they do without using management models and implementing improvement systems. Also, entrepreneurs who develop small businesses usually have little desire to establish routine processes and procedures. On the other hand, large organizations often have strategic planning departments, more people who have encountered management models and strategic concepts when they completed their management or other college degrees, more money to spend on training, and large competitors which are strategically focused and competitively driven.

Leitner (2007) carried out a longitudinal survey of SMEs in Austria in two surveys in 1995 and 2003. The purpose of the research was to find out the role and nature of different strategy-making modes in 91 SMEs. The results revealed that most of the SMEs had, at the same time in at least one area, a deliberate strategy. Interestingly, only one company was found to be a pure emergent strategist. The conclusion was that companies were combining different strategy-making modes simultaneously. These findings are consistent with the findings of Menzel and Günther (2012) who also observed a lack of formal strategic management in SEs in their 2-year in-depth qualitative single-case study of 65 employees working in a medium-sized enterprise in Germany. They concurred that strategy making in small firms is emergent, adaptive, and based on personal relationships.

In another survey of 500 small- and medium-scale manufacturing concerns in the United States of America, Metts (2011) investigated the role of adaptive decisionmaking and its potential significance in strategy making in small- and medium-sized manufacturing companies and found that adaptive decision-making plays a significant role in the formation of strategy in manufacturing SMEs. He proposes an adaptive decision-making where the managers try to avoid uncertainty by searching for reactive solutions to existing problems. However, the study was also conducted in the context of a developed country. Besides, the study did not compare whether the adaptive processes led to better performance than other informal modes of strategic management which this study addresses. 
On a slightly different vein, Sidaya (2006) carried out a study whose main purpose was to analyze what strategies small and medium businesses actually adopt when confronted with a major crisis such as a fire, flood, or similar catastrophe and determine what factors proved vital to the survival of the business in Australia. A qualitative approach was taken, which involved interviews and in-depth analysis of 12 case studies. To develop a model, many components of earlier models of strategic management were tested for relevance to the manager during a major crisis in the business. The study found that the owners and managers of small and medium businesses rated the development of a Crisis Management Model (CMM) as a crucial management tool to assist them to fight for the survival of their business following a crisis. Though the study findings were consistent with reactive strategies in the context of strategic issue management, it concentrated only on a one-off crisis management and not on the day-to-day management experience of small enterprises which this study intends to reveal.

In another survey exploring the adoption of formal strategic management practices among the small and medium enterprises within Mombasa County in Kenya, Irungu (2011) found out that a majority (53\%) of the SEs had documented their strategy process in the form of written plans and objectives. However, the communication of the plans was not elaborated as 53\% communicated by word of mouth indicating an informal communication system. The study thus concluded that the extent of adoption of formal strategic management practices among SMEs within Mombasa County was still low. This study goes a step further by examining why small enterprises resort to informal strategic management practices. In his study seeking to determine the strategic planning practices adopted by micro and small business in Kisumu Central Business District, Mutua (2012) also found that micro and small firms practiced strategic planning to varied degrees. However, the average rate of adoption of the strategic planning practices still fell below levels required for spur sustained growth and survival especially for those firms within Kisumu Central Business District. The study also revealed a gap between formulation of strategic plans and their implementation. The study noted that SMEs seemed to over-concentrate on short-term operational issues as at the expense of long-term strategic issues. Further, in a survey on strategic management practices in small and medium enterprises at Kariobangi Light Industries, Nairobi, Kiruja (2011) also concludes that most of the firms surveyed did not have any formal strategic management mechanisms. These studies revealed interesting findings on the adoption of formal strategic management practices among small enterprises. These study findings therefore remain at discovering whether small enterprises practice formal strategic management or not. However, the studies did not examine whether informal strategies played a role in leveraging performance of small enterprises, neither did they delineate factors debilitating performance of the small enterprises employ. This study therefore goes a step further by examining the influence of each of the factors against strategies of the small enterprises.

Earlier on, Mintzberg and Waters (1985) had carried out a study which involved 11 intensive cases, including a food retailer, a manufacturer of women's undergarments, a magazine, a newspaper, an airline, an automobile firm, a mining company, a university, an architectural firm, a public film agency, and a government fighting a foreign war in America. Their conclusion was that strategy was emergent, forming patterns of decisions and actions distributed across multiple organizational levels, and only partially 
shaped by managerial intentions and that strategy making in small firms was an informal process resulting in a pattern of decisions by top management. Similarly, Quinn (1980), drawing on a survey of ten major corporations in America, demonstrates how top management typically forge their strategies for change only gradually as events unfold, keeping their options open and steering their organizations incrementally towards a consensus view of the major important goals to be attained. He posits that effective strategies tend to emerge from a series of 'strategic subsystems', each of which attacks a specific class of strategic issues (e.g., acquisition, divestiture, or a major reorganization) in a disciplined way, but which is blended incrementally and opportunistically into a cohesive strategy. Again, both studies, though informative as to the strategic management modes small enterprises are likely to take, were undertaken in developed countries with none being done in the context of a developing country. Further, the studies only explore the nature of strategy making in small enterprises but do not tie them to performance.

\section{Empirical studies on factors influencing choice of strategic management mode}

According to Cragg and King (1988) and Rutherford and Oswald (2000), the factors that influence whether a small enterprise chooses a particular strategic management mode may be due to own personal characteristics; as captured in personal entrepreneurial competency, small firm characteristics; in terms of scope, scale, ownership structure and size, and external environmental factors; and in terms of political, economic, sociocultural, technological, and ecological. Each of the factors is discussed below.

\section{Small firm characteristics}

Small firm characteristics have been explored by various authors in different contexts. For example, in Bangladesh, Obaidullah et al. (2011) carried out a survey whose purpose was to find out whether firm characteristic affects the business success in smalland medium-sized enterprises. Interestingly, the findings of the study revealed that while entrepreneur's characteristics are significantly related to the business success of SEs in Bangladesh, the characteristics of small enterprises were found to have no significant effect on the business success of the SEs. In contrast to these findings, Monsicha and Nantana (2011), in a survey of 410 travel agencies in Thailand, examined the relationships between firm characteristics such as corporate image, unique attributes, service, and service professionalism that influence customer satisfaction and customer loyalty and found out that the firm characteristics have greater business outcomes, including customer satisfaction, customer loyalty, and business performance.

Although the studies help us to understand that a majority of SEs do not perform well because of the very nature of their firms, they did not examine whether the small firms were, in fact, not doing well because the nature of the firms militated against being formal in their management. This study explored whether small firm characteristics militated against their performance because the firm characteristics made it difficult to manage the firms strategically. The small enterprises need an all-inclusive intervention which these studies did not offer and which this study intends to explore.

Further, M. Pasanen, (Unpublished Work) carried out a survey of entrepreneurs of 145 independent SEs in eastern Finland operating in the manufacturing, business 
services, and tourism sectors. Analysis of the SMEs revealed that they constitute a heterogeneous group with a large variety of characteristics, though they also have some common characteristics. However, the study does not conclusively delineate the actual characteristics of the SEs that predispose them to particular strategic modes.

On his part, Jiang (2009) carried out a case study of SEs in China and Indonesia. The objective of the study was to find out how strategic management influences SE performance in Southeast Asia and specifically in China and Indonesia. According to the empirical findings, they found some common characteristics of strategic management of SEs in China and Indonesia. Firstly, all the companies interviewed had their decision-making system centralized. In most occasions, the general managers or owner made the final decisions. Secondly, all the companies had a clear vision and mission for the company, and they made sure all the employees within the organization knew the company's objectives. Thirdly, all of the SEs used a combination of formal and informal structure during the strategic implementation process. Fourthly, they paid great attention to government policy and changed their strategies according to government policy. Last but not the least, they all believed that strategic management could affect company performance from financial and non-financial aspects. However, the findings of the study are rather inconsistent with reviewed theoretical literature. According to Gibbons and O'Connor (2005) and Johnson et al. (2011), small firms' managers are so inundated with immediate financial problems that they ignore or even misunderstand the link between sound strategic management practices and business success rendering formal strategic management modes irrelevant to small firm managers. For example, in an empirical review of implications of strategic planning in SEs for international entrepreneurship research and practice, Kraus et al. (2007) posit that considerable strategic differences exist between small and large enterprises. Because of their small size, small firms are not structured formally and the decision-making process is centralized. While important in revealing the small firm characteristics that are required for small firm performance and the relationship between formal strategic management and performance of the small firms, the studies did not explore the connection between firm characteristics and informality of the small firm management. This study explores the small firm factors that may discourage or encourage small firms to be informal.

Le Roux (1989) also conducted a survey of 300 SEs in the Greater Cape Town area, South Africa and found that the managers and owners of SE's value strategic management as a management tool, but for various reasons, such as a lack of time, they did not devote as much time as they would like towards managing strategically. The study also found no support for the assumption that size would be an important factor distinguishing SEs that made use of strategic management from those SEs that did not use strategic management but rather the process of strategic management itself was more important than the actual formal plans and documentation that are normally associated with strategic management in large organizations. In summary, there is a general dearth of empirical literature on the link between firm characteristics and informal strategic management modes.

\section{The external factors}

Despite their role in terms of their contribution to exports, employment, and economic growth, there is a wide recognition in the literature about the environmental challenges and barriers facing SEs (Verreynne and Meyer 2007). These prevent them from growing 
further and put them in a critical position to face the external challenges that are arising from globalization, liberalization, and technological change. According to Morrison (2006), businesses are so affected by external macro-environments that they cannot plan political, economic, social, technological, environmental, and legal factors facing them.

Gica (2012) surveyed 200 SEs in northwestern Romania and found the external analysis component of the overall planning indicator to be positively correlated with a higher level of objective achievement with a confidence level of $99 \%$. The variables used to measure the external environmental components were the political, economic, sociocultural, technological, and ecological factors. The conclusion was that the extent to which objectives are met is influenced by an analysis of opportunities and threats facing the organization as well as an assessment of strengths and weaknesses.

Tenai et al. (2009) carried out an exploratory survey on the external variables moderating SE's strategies and competitiveness for international trade in Kenya. The survey covered 50 horticultural traders in urban and peri-urban areas of Uasin Gishu District in the month of September 2007. These findings suggest that the nature of the business environment dictates the way the firm is operated. Hence, the prevailing strategy may be influenced positively if the moderating factors from both sides positively moderate it. The strategic management is unlikely to be strong if the firm is weak internally, thus hampering its ability to capture opportunities and satisfy them in a dynamic and uncertain market. Such opportunities may include credit access, severe price competition, and learning ability.

The studies investigated the extent to which external factors influence the achievement of objectives, but did not enquire the influence of the external factors on informal strategic management modes. The studies therefore concentrated only on the effect of formal strategic management and did not explore the informal strategic management practices, neither did the studies explore how the factors moderated the types of informal strategic management modes being employed by small enterprises which this study investigated.

In China, Huang (2011) carried out a case study whose purpose was to examine the process and characteristics of strategic decision-making (SDM) and their influencing factors in 20 Chinese small- and medium-sized firms. The findings of the study revealed that the steps involved in the SDM process in Chinese SEs are less complex than the theoretical models; second, Chinese SME owners/managers rely heavily on their personal networks for identifying opportunities in the business environment and for information search and advice; third, a firm's ownership significantly influences the degree of participation and the level of political activities in the SDM process; and fourth, decisions made in Chinese SEs can be implemented quickly partly due to slack legal enforcement in China. The purpose of the study was to examine the process and characteristics of SDM and their influencing factors in Chinese small- and medium-sized firms. However, the study did not delineate informal strategic management modes that small enterprises have been found to prefer. Further, the study did not reveal the actual strategic management mode influenced by each of the external environmental variable.

Ghani et al. (2010) carried out a descriptive research study to identify critical internal and external factors towards firm strategic planning among private housing developers of Kedah and Perlis in Malaysia and found out that proactive involvement of government and its support did have an impact on firms' external critical factors thereby 
creating stable conditions for structured planning. However, the study did not address whether this proactive environment facilitates strategic management. Besides, the study dealt only with private housing developers while this study takes a holistic approach to strategic management of small enterprises. In an exploratory study on government policy and critical success factors of small businesses in Singapore, Siow and Teng (2011) also report that the government plays a very critical role in assisting businesses in general by providing a conducive environment for the growth and development of the businesses and this may facilitate strategic planning.

Martínez (2009) surveyed 72 Spanish footwear entrepreneurs in Spain in the year 2000. The survey was a cross-sectional empirical analysis whose purpose was to test the contribution of different types of entrepreneurship development programs to new business performance and growth. The study reinforced earlier research that sound SE policy environment significantly favors new business profitability and growth. In a multiple-case study design involving three companies, four organizations cooperating with SEs, and two academic institutions, Grimsholm and Poblete's (2010) carried out a study whose purpose was to examine external environmental aspects of SEs that were hampering the growth of SEs in Thailand and summarized the factors as lack of access to finance, competition, barriers to trade, lack of skilled labor, and new technology.

Again, the studies concentrated on the influence of external factors on firm strategic planning but did not tie the external factors to the informal modes of strategic management. The studies therefore were important in revealing whether the external environment had an effect on performance when they engaged in formal strategic planning. However, the studies made no reference to the informal modes of strategic management. This study attempted to reveal how external factors influenced the informal strategic management small enterprises employed.

\section{Personal characteristics}

In a survey on the impact of personality traits on firm performance in Malay family businesses, Zainol and Ayadurai (2011) concluded that although it is difficult to measure entrepreneurial orientation (EO) through personality traits due to the many aspects involved, entrepreneurs who had a higher tolerance of ambiguity than non-entrepreneurs, a higher level of self-efficacy, a more proactive personality, an internal locus of control, and a stronger need for achievement were more likely to plan for the success of their businesses. They observed that even in more complex decisions involving the need to develop careful plans, values played a relevant role. More goal orientation induced a stronger motivation to plan thoroughly. The higher the priority given to a value, the more likely people will form action plans that can lead to its expression in behavior, namely, performance. They conclude that owner's personality has a direct relationship with the performance of firms in Malaysia.

In another study conducted with 147 SE owners in Malang Regency, East Java Indonesia using the survey method, Sarwoko et al. (2013) found performance of small business to be determined by the characteristics of the owner/manager. They define the entrepreneurial characteristics in terms of risk taking, innovation, and proactiveness. Baba and Elumalai (2011) also investigated the relationship between entrepreneurial orientation dimension and organizational performance indicators such as product performance, customer performance, and sales growth among SMEs in Labuan. A total of 
101 SMEs were selected. These sampled establishments were involved in servicerelated business, retail business, and also wholesale. The study concluded that risk taking, innovation, proactiveness, and competitive aggressiveness have significant positive relationship with organizational performance.

Qureshi (2012), confining himself to five research variables, i.e., motivation, family support, social networking, personal characteristics, and culture, examined the factors that influenced the small business performance among the males and females in Pakistan. The analysis was based on a survey of 200 micro businesses owned by males and females in two cities of Pakistan, namely, Lahore and Faisalabad. The results showed that femaleowned businesses in Punjab-Pakistan were less successful than male-owned businesses because females possessed less such personal characteristics which were critical for success in business. He also found that females encountered barriers in making social networks as compared to males. The study also revealed that the culture of the society also limited opportunities for female entrepreneurs to grow and outperform male-owned businesses.

Although the studies had far-reaching implications on personal characteristics that may hinder small business success, they did not address the strategic management aspect to performance, neither did they explore if the performance was due to the informality of their management which this study strives to reveal. This study therefore goes a step further by exploring the relationship between owner characteristics, the informal strategic management mode employed, and the performance of small enterprises.

Moog et al. (2011) basing their research on six qualitative case studies conducted in Germany in 2008 observed that personal or individual orientations of the owners, predecessors, and successors affect the strategy and performance of their family businesses. They concluded that the individual orientation of previous, current, and future owners of a family business might be the key to those differences in performance of such businesses. They also found out that in small entrepreneurial organizations, the strategic decisionmaking is vested with the entrepreneur or limited number of trusted individuals. The strategy formulation for growth is driven by the vision and motivation of the entrepreneurs. Again, the two were interested in the determinants of strategic planning and not the modes of strategic management the small enterprises were using.

In a study carried out in Australia to explain the apparent problem of why SMEs do not strategically plan, Wang and Walker (2012) postulate that ownership motivations are central to understanding the planning practices in SMEs. They found that levels of strategic planning are higher in SMEs which have owner-managers who are growth orientated and lower in those which have owner-managers who pursue non-economic personal agendas. However, they noted that many owner-managers of SMEs do not want to grow and are happy with staying small and at one end of the continuum; some were simply keeping themselves gainfully employed. They pointed out that although this was not necessarily a bad thing, many businesses were not 'entrepreneurial' and never engage in active growth activities including strategic planning. Consequently, ownership motivation, not organizational barriers to planning, must be taken as a starting point to understanding and solving the issue of why most SMEs do not engage in strategic planning. However, from the various literature reviewed, it has been posited that lack of conventional strategic planning is not necessarily a lack of strategic planning per se (Chia 2007). The two researchers also did not examine the link 
between informal strategic management modes, owner characteristics and, SE performance.

Using the survey method, Hajipour and Ghanavati (2012) also analyzed small- to medium-sized industrial manufacturing firms in Tehran province in Iran and found a relationship between education and small firm performance. They observe that education is important in the upbringing of the entrepreneurs. Its importance is reflected not only in the level of education obtained but in the fact that it continues to play a major role in helping to cope with problems and correcting deficiencies in business training. Entrepreneurs need education in the areas of finance, strategic planning, marketing (particularly distribution), and management. The ability to deal with people and to clearly communicate in the written and spoken word is important in any entrepreneurial activity. Although the findings reveal that education as a personal entrepreneurial factor affects business performance, this study takes a broader look by questioning the link between personal characteristics and informality of small enterprises.

Franczak et al. (2009) also surveyed 857 respondents from 21 small- and medium-sized companies in the UK and found a strong correlation between culture and organizational performance. In another study involving a sample of 60 Fortune 1000 firms representing both dominant and lesser members of their respective industries, Hansen and Wernerfelt (2007) found a relationship between people factors such as skill, personality, age, and firm performance. In yet another study involving a sample of 300 employees from SMEs in Bangladesh, Obaidullah et al. (2011) found out that entrepreneurs' characteristics have significant effect on business performance of SMEs in Bangladesh. The study was based on survey methodology through a questionnaire administered on the owners and employees of small firms. They observed that small business owners must have a missionary zeal about their products or services, be willing to be personally involved in it, be willing to stick with the business, and be able to define the market clearly and pay attention to details. Antecedent influences on owner-managers showing a significant association with the possession of a business plan included an above average level of education, previous work experience in a large firm immediately before setting up their firm, and running firms in sectors outside their previous experience. Not surprisingly, possession of a business plan showed a positive association with those owner-managers with a growth orientation. It is concluded that owner-manager characteristics can be important in explaining the presence/absence of a business plan within the small firm.

\section{Results-and-discussion}

Data was collected from 150 respondents, but only 113 returned complete responses. This formed a response rate of $75 \%$. According to Mugenda (2013), a response rate of $70 \%$ or higher is acceptable in social science research.

\section{Study population}

The unit of analysis for this study was the small enterprises. The study targeted all the 7,324 small enterprises in Kisumu County (Mutua 2013). The accessible population was all the 252 small businesses that had been funded by the Youth Enterprise Development Fund in Kisumu County since the year 2007 and six district youth officers. 


\section{Sampling design}

This study adopted Yamane (1967) formula to calculate the sample size for the youth groups. The formulae yielded 150 respondents from the population of 242 youth enterprises. The study adopted stratified, simple, and purposive sampling techniques to select the SEs and the individual respondents. Stratified random sampling was used to select the SEs that had benefited from the Youth Enterprise Development Fund. Simple random sampling was used to select the individual SEs in each constituency. Purposive sampling was used to select the six key informants. Therefore, the total sample size was 157 with 150 being the small enterprises run by beneficiaries of the Youth Enterprise Development Fund and six DYOs. The managers of each of the 150 SEs were included as respondents for this study.

\section{Data collection methods and tools}

The study adopted questionnaire and interview methods as the basic data collection methods (Additional file 1). Questionnaires were used to gather data from the managers of the small enterprises. The interview method was used to collect data from the six key informants.

\section{Validity and reliability}

The CVI for this study was $81.8 \%$. Further, the principle of triangulation was employed to collate the results from the questionnaire and key informant interviews. Pre-testing of the tools was undertaken on 30 leaders of YEDF group beneficiaries in Bondo Township before administering the full-scale interview to ensure clarity of the instruments. The internal consistency of the interview schedule was then determined via Cronbach's coefficient alpha (Cronbach 1951). In this study, the Cronbach's alpha for each of the variables scales was tested and found to be above $70 \%$.

\section{Data analysis method}

This study collected and analyzed both quantitative and qualitative data. Quantitative data was analyzed using descriptive statistics, multiple regressions, and Pearson's correlation coefficient $(r)$. Qualitative data was analyzed using content analysis.

\section{Methods}

The study adopted a cross-sectional survey design. According to Tuli (2012), the selection of research methodology should depend on the paradigm that guides the research activity, more specifically, beliefs about the nature of reality and humanity (ontology), the theory of knowledge that informs the research (epistemology), and how that knowledge may be gained (methodology). The aim of this research was to explore the factors that the choice of strategic management modes employed by small enterprises in Kisumu County with particular reference to beneficiaries of Youth Enterprise Development Fund in rural Kenya. Being a descriptive crosssectional research design, the ontological orientation of the study is that of the realist assumption. 


\section{Strategic management modes employed YEDF beneficiaries}

The informal strategic modes were conceptualized as deliberate, emergent, and reactive strategies. Deliberate strategies were measured by the presence of formal written down plans and strict adherence to those plans, while the emergent strategies were measured by absence of formal plans and reliance on past experiences and industry tradition. The reactive strategies were measured by both absence of formal plans and reliance on instincts as strategic issues arise. The three strategic management modes were proposed and explained to the respondents. The respondents were then asked to choose which mode suited their operations most. The results were analyzed and presented in Table 1.

Table 1 shows that most (58\%) of the respondents rated the reactive strategic management mode as the most preferred mode of strategic management $(N=64$, mean $=$ 2.58) followed by the emergent strategic management mode $(N=40$, mean $=2.28)$, and the least preferred mode was the deliberate strategic management mode $(N=9$, mean $=2.22$ ). This shows that although the deliberate strategic management mode has been the preferred perspective of strategy making and implementation for government functionaries and other agencies involved in molding small-scale enterprise, this study revealed mixed reactions to this form of management. Thus, the small enterprises have a preference for the reactive strategic management mode. The implication of this finding is that, despite their training in formal strategic management, the small enterprises preferred to make decisions based on their instincts as strategic issues arose. This resounds with the views of Chaffee (1984) and Metts (2011) who also see an organization as continually assessing external and internal conditions, and this leads to adjustments in the organization to its relevant environment that will create satisfactory alignments of environmental opportunities and risks, on the one hand, and organizational capabilities and resources, on the other. This strengthens the hypothesis that although the small enterprises could be exposed to deliberate strategies where formality of strategic management is espoused, they do not plan formally, and for those that plan, only a few follow these plans. Rather, the small business owner operates along market conditions and reacts to opportunities and threats as they come.

\section{Factors influencing choice of strategic management modes}

Having established that the respondents use the three different strategic management modes interchangeably, the study sought to find out the factors that influenced the respondents to adopt any of the particular strategic management modes. The predictors were therefore the small firm characteristics (FIRM), the external environmental factors (ENVT), and the small firm owner's personal factors (PEC), while the dependent variables were the strategic management modes, namely, deliberate strategic management

Table 1 Views on the most preferred strategic management mode

\begin{tabular}{lccc}
\hline Strategic management mode & Mean & Number & Percent \\
\hline Deliberate & 2.22 & 9 & 8.2 \\
Emergent & 2.28 & 40 & 35.0 \\
Reactive & 2.58 & 64 & 56.8 \\
Total & 2.45 & 113 & 100.0 \\
\hline
\end{tabular}


mode (DEL), reactive strategic management mode (RE), and emergent strategic management mode (EM).

\section{Factors influencing choice of deliberate management mode}

Pearson product-moment correlation coefficient was used to investigate the relationship between the factors that influence the choice of deliberate strategies. Preliminary analyses were conducted to ensure no violation of the assumptions of normality, linearity, multicollinearity, and homoscedasticity. The results of the Pearson's $r$ are presented in Table 2 .

Table 2 presents the correlation coefficient between the factors and deliberate strategic management mode (DEL). There is no significant correlation at $p<.05$, but there are significant correlations at $p<.01$. Table 2 also shows that there is a positive and significant correlation between DEL and PEC $\left(r=.348, r^{2}=.0121\right)$. This indicates that the personal characteristics of a manager of a SE play a significant role in the choice of deliberate strategic management mode. This finding supports Zainol and Ayadurai (2011) views when they observe that the entrepreneurial orientation of the owner manager of a SE plays a significant role in whether or not formal planning and management takes place in a small business.

There being a significant correlation, the study then proceeded to test the individual predictors against the deliberate strategic management mode (DEL). The individual predictors were regressed on DEL under the hypothesis that personal characteristics, environmental characteristics, and firm characteristics are not significant determinants of choice of deliberate strategic management mode.

The results of the analysis are summarized in Table 3.

Table 3 shows that the overall regression model is significant $(F[3,109]=19.471$, $p=.000)$ which led to the rejection of the null hypothesis. The study therefore established that at least one of the factors (FIRM, ENV, and PEC) is a significant determinant of deliberate strategy.

The individual factors were further investigated using $t$ values to determine the significant determinants since the $F$ value indicated that not all the predictors are significant. The analysis of $t$ values indicates that only PECt is a significant determinant $(t[113,109]=6.309$, $p=.000)$. But FIRMt $(t[113,109]=-.006, p=.995)$ and $\operatorname{ENV}(t[113,109]=1.998, p=.046)$ are not significant. A regression model for predicting deliberate strategic management mode was then generated using the $B$ values and the constant as:

$$
\mathrm{DEL}=.351+.025 * \mathrm{PEC}
$$

The adjusted $R^{2}\left(R^{2}=0.124\right)$ indicates the total variance in deliberate strategy explained by the regression model in Equation 1 . It indicates that $12.4 \%$ of the total variance in DEL is explained by PEC.

Table 2 Analysis of factors influencing choice of deliberate strategic management mode

\begin{tabular}{lcccc}
\hline & DEL & FIRM & PEC & ENV \\
\hline DEL & 1 & .077 & $.348^{* *}$ & $.204^{* *}$ \\
FIRM & & 1 & $.132^{* *}$ & $.340^{* *}$ \\
PEC & & 1 & $.315^{* *}$ \\
ENV & & & \\
\hline${ }^{*} p<.05 ;{ }^{* *} p<0.01$. & & & & 1 \\
\hline
\end{tabular}


Table 3 Factors influencing choice of deliberate strategy

\begin{tabular}{lccccccccc}
\hline Model & $\boldsymbol{B}$ & Beta & $\boldsymbol{R}$ & $\boldsymbol{R}^{\mathbf{2}}$ & $\mathbf{A d j} . \boldsymbol{R}^{\mathbf{2}}$ & $\boldsymbol{\varepsilon}$ & $\boldsymbol{F}$ & $\boldsymbol{t}$ & Sig. $(\boldsymbol{e})$ \\
\hline Constant & .351 & & & & & .154 & & 2.287 & .023 \\
FIRM & .000 & .000 & & & & .014 & & -.006 & .995 \\
PEC & .025 & .315 & & & & .004 & & 6.309 & .000 \\
ENV & .020 & .105 & & & & .010 & & 1.998 & .046 \\
Summary & & & .362 & .131 & .124 & & 19.471 & & \\
\hline
\end{tabular}

Thus, SEs managed by people who are entrepreneurially competent tend to employ formal plans and vice versa. For a SE managed by a manager high in personal entrepreneurial competence, there is $12.4 \%$ chance that $\mathrm{s} /$ he will adopt a deliberate mode, but $87.6 \%$ of the variance would be due to other factors. This finding supports the views of Wang and Walker (2012) and De Koning and Brown (2001) when they observe that strategy formulation for growth is driven by the vision and motivation of the entrepreneurs and that levels of strategic planning are higher in SEs which have ownermanagers who are entrepreneurially orientated.

\section{Factors influencing choice of reactive management mode}

Having established that personal entrepreneurial competency and environmental factors are significant determinants of a deliberate strategic management mode, the study sought to find out which of the factors influenced the respondents to employ the reactive strategic management mode (SIMR). Pearson product-moment correlation coefficient was used to investigate the relationship after preliminary analyses. The results of the Pearson's $r$ are presented in Table 4.

Table 4 shows that there is no significant correlation at $p<.05$, but there are significant correlations at $p<.01$. The table also shows that there is a positive and significant correlation between both RE and PEC $\left(r=.172, r^{2}=.030\right)$ and RE and FIRM $(r=.196$, $\left.r^{2}=.038\right)$. This indicates that both the personal characteristics of the small business manager and the small firm characteristics play a significant role as to the choice of reactive strategic management mode chosen.

The study then proceeded to test the individual predictors against RE. The individual predictors were regressed on RE under the hypothesis that personal characteristics, environmental characteristics, and firm characteristics are not significant determinants of choice of a reactive strategic management mode.

The results are summarized in Table 5.

Table 5 presents the summary of the regression analysis of factors influencing choice of RE. The table shows that the overall regression model is significant $(F[3,109]=$

Table 4 Factors influencing choice of reactive strategic management mode

\begin{tabular}{lcccc}
\hline & RE & PEC & ENV & FIRM \\
\hline REL & 1 & $.172^{* *}$ & .093 & $.196^{* *}$ \\
PEC & & $.315^{* *}$ & $.132^{* *}$ \\
ENV & & & $.340^{* *}$ \\
FIRM & & & 1 \\
\hline${ }^{*} p<.05 ;{ }^{* *} p<0.01$. & & & &
\end{tabular}


Table 5 Summary of the regression analysis of factors influencing choice of SIMR

\begin{tabular}{|c|c|c|c|c|c|c|c|c|}
\hline Model & $B$ & $R$ & $R^{2}$ & Adj. $R^{2}$ & $\varepsilon$ & $F$ & $t$ & Sig. (e) \\
\hline Constant & .839 & & & & .162 & & 5.180 & .000 \\
\hline FIRM & .050 & & & & .014 & & 3.471 & .001 \\
\hline PEC & .012 & & & & .004 & & 2.952 & .003 \\
\hline ENV & -.003 & & & & .011 & & -.304 & .761 \\
\hline Survey model & & .246 & .061 & .053 & & 8.315 & & \\
\hline
\end{tabular}

8.315, $p=.000$ ) which led to the rejection of the null hypothesis. Having established that the two factors are significant determinants of RE, the study proceeded to investigate the individual factors using $t$ values to determine the significant determinants since the $F$ value indicated that not all the predictors are significant.

The $t$ values indicate that both FIRM and PEC are significant determinants, $(t$ [113, $109]=3.471, p=.001)$ and $(t[113,109]=2.952, p=.003)$, respectively. ENVt $(t[113$, $109]=-.304, p=.761)$ is not significant. A regression model for predicting reactive strategic management mode was then generated using the $B$ values and the constant as:

$$
\mathrm{RE}=.839+.050 * \mathrm{FIRM}+.012 * \mathrm{PEC}
$$

The Adj. $R^{2}=.053$ indicates the total variance in reactive strategy explained by the regression model in Equation 2. This indicates that $5.3 \%$ of the total variance in REL is explained by FIRM and PEC. Thus, 5.3\% of the variance in REL is due to PEC and FIRM, while $94.7 \%$ are due to other factors not investigated including errors in measurement. This means that the characteristics of the firm have the greatest impact as to whether a firm resorts to reactive strategic management mode followed by individual characteristics of the manager of the small firm. The smaller the enterprise, and the less entrepreneurially competent the SE manager, the more likely s/he will employ a reactive mode of strategic management and vice versa. This finding is consistent with Obaidullah et al.'s (2011) observation that that antecedent influences on ownermanagers of small business such as an above average level of education, previous work experience in a large firm immediately before setting up their businesses, as well a missionary zeal about their products or services and willingness to be personally involved in running the business play a role in whether a small business manager plans and sticks to those plans. Kraus et al. (2007) posit that considerable strategic differences exist between small and large enterprises. Because of their small size, small firms are not structured formally and the decision-making process is informal.

\section{Factors influencing choice of emergent management mode}

The factors that influenced the respondents to employ the emergent strategic management mode (EM) were also analyzed. Pearson's $r$ was again used to investigate this relationship. The results are presented in Table 6.

Interestingly, the same values accruing from the analysis of reactive strategies were observed in the analysis of emergent strategies. The correlation in Table 6 shows that there is a positive and significant correlation between both EM and PEC $(r=.172$, $\left.r^{2}=.030\right)$ and EM and FIRM $\left(r=.196, r^{2}=.038\right)$. This indicates that both the personal characteristics of the small business manager and the small firm characteristics play a 
Table 6 Factors influencing choice of emergent strategic management mode

\begin{tabular}{lcccc}
\hline & EM & PEC & ENV & FIRM \\
\hline EM & 1 & $.172^{* *}$ & .093 & $.196^{* *}$ \\
PEC & & $.315^{* *}$ & $.132^{* *}$ \\
ENV & & & $.340^{* *}$ \\
FIRM & & & 1 \\
\hline${ }^{*} p<.05 ;{ }^{* *} p<0.01$. & & &
\end{tabular}

significant role as to the choice of reactive strategic management mode for running the businesses.

Individual predictors were also tested against EM under the hypothesis that personal characteristics, environmental characteristics, and firm characteristics are not significant determinants of choice of reactive strategic management mode. The summary of the results are presented in Table 7.

Table 7 shows that the overall regression model is significant $(F[3,109]=8.315$, $p=.000)$ which led to the rejection of the null hypothesis. The study then proceeded to investigate the individual factors using $t$ values to determine the significant determinants. This finding confirms.

The $t$ analysis indicates that both FIRM and PEC are significant determinants, $(t$ $[113,109]=3.471, p=.001)$ and $(t[113,109]=2.952, p=.003)$, respectively. ENV $(t$ $[113,109]=-.304, p=.761$ ) was not a significant determinant of EM. A regression model for predicting emergent strategic management mode was again generated using the $B$ values and the constant as:

$$
\mathrm{EM}=.839+.050 * \mathrm{FIRM}+.012 * \mathrm{PEC}
$$

The Adj. $R^{2}=.053$ indicates the total variance in emergent strategy explained by the regression model in Equation 3. This indicates that $5.3 \%$ of the total variance in EM is explained by FIRM and PEC. The $94.7 \%$ is due to other factors not investigated including errors in measurement.

\section{Summary of findings, conclusions, and recommendations}

On which strategic management mode the small enterprises employed in seeking better performance for their businesses, the study revealed that the respondents used all the three strategic management modes to varying degrees. This means that although the deliberate strategic management mode has been the preferred perspective of strategy making and implementation for government functionaries and other agencies involved in molding small-scale enterprises in Kenya, the small enterprises were not following their training. This further proves that conventional thinking was inappropriate for the

Table 7 Summary of the regression analysis of factors influencing choice of EM

\begin{tabular}{lcccccccc}
\hline Model & $\boldsymbol{B}$ & $\boldsymbol{R}$ & $\boldsymbol{R}^{\mathbf{2}}$ & $\mathbf{A d j} . \boldsymbol{R}^{\mathbf{2}}$ & $\boldsymbol{\varepsilon}$ & $\boldsymbol{F}$ & $\boldsymbol{t}$ & Sig. $(\boldsymbol{e})$ \\
\hline Constant & .839 & & & & .162 & & 5.180 & .000 \\
FIRM & .050 & & & & .014 & & 3.471 & .001 \\
PEC & .012 & & & & .004 & & 2.952 & .003 \\
ENV & -.003 & & & & .011 & & -.304 & .761 \\
Survey model & & .246 & .061 & .053 & & 8.315 & & \\
\hline
\end{tabular}


small firms. The study also disapproves scholars who prescribe only to the emergent strategy management processes and brings to the fore the need for more emphasis on formalization of reactive models that address the reactive mode of strategic management in strategic management literature and in practice.

The study also assessed the factors influencing the choice of strategic management mode employed by small enterprises in Kisumu County. The results revealed that the personal entrepreneurial characteristics were the main determinant of the strategic posture of a small enterprise. This means that the more competent a small firm manager is, the greater the chances that s/he would be formal. Environmental and firm factors notwithstanding, the personal entrepreneurial competency of the small firm manager would improve the performance of the small enterprise.

\section{Conclusions}

The results show that small enterprises in Kisumu County use all the three modes of strategic management, but they tend to rely on the reactive strategic management mode more. Indeed, the least employed mode of strategic management was the deliberate strategic management mode. This means that formal strategic management is inadequate for the performance of small firms. The study concludes that there is a need for educationists and scholars to put more emphasis on informal strategic management models that address the reactive modes of small firms.

The study also found out that the more competent a small firm manager was, the greater the chances that s/he would perform well in his/her business. Environmental and firm factors notwithstanding, the PEC of the small firm manager would improve the performance of the small enterprise. The implication for this study is that, although PEC factors are largely absent in strategic management literature, they form an important ingredient as to whether a firm succeeds or not. The study concludes that small firm scholars and educationists should put more emphasis on exposing small enterprises to the elements of the PEC model even as they address the environmental and firm issues.

Since the SEs employ both forms of strategic management to varying degrees, the study recommends that there is a need to come up with an effective strategic management system in SEs to de-emphasize the need for formal written documentation, reports, and activities as a means to recognizing the contribution of informal strategic management processes. Important as they are, such a system should lay less emphasis on the abstract notions like broad goals, business mission, and long-term objectives as a prerequisite to a meaningful strategic management process. In essence, the SEs should also be exposed to informal strategic management models that would inform decisions on upcoming strategic issues even as they exploit the stock of existing knowledge. Indeed, as the review of literature has revealed, there exists a small percentage of small enterprises that have succeeded even as they employ informal strategic management. Examples of such models include strategic issue management (SIM) model and the knowledge creation spiral (KCS) model.

As the study has revealed, although small firm managers may be entrepreneurially competent for strategy making and implementation, their failure may stem from the 
very nature of the firms and the environments in which they operate. Policy makers, researchers, and small firm sector players must therefore look towards models that expose small enterprises to the understanding of the fluid nature of their environments in respect to their firm characteristics. Specifically, small firm scholars and educationists should put more emphasis on exposing small enterprises to the elements of the PEC model even as they address the environmental and firm issues.

\section{Additional file}

Additional file 1: Informal strategic management modes and performance of small-scale enterprises.

\section{Competing interests}

The authors declare that they have no competing interests.

\section{Authors' contributions}

NAC Conceived the study, performed the statistical analysis and drafted the manuscript. PBO and OD participated in the sequence alignment and the design of the study. All authors read and approved the final manuscript.

\section{Author details}

${ }^{1}$ Department of Project Planning and Management, School of Business Management and Public Administration, Amoud University, Borama, Somaliland. ${ }^{2}$ Department of Marketing and Management, School of Business and Economics, Maseno University, Maseno, Kenya. ${ }^{3}$ Department of Business and Finance, School of Business and Economics, Maseno University, Maseno, Kenya.

Received: 8 July 2014 Accepted: 16 December 2014

Published online: 07 March 2015

\section{References}

Amenya S, Onsongo O, Guyo H, Onwong'a M. (2011). An analysis of the challenges facing Youth Enterprise Development Fund: a case study of Nyaribari Chache Constituency, Kenya Available online: http://www.aibuma. org/proceedings2011

Ansoff, HI. (1965). Corporate strategy. New York: Wiley.

Baba R, Elumalai S (2011). Entrepreneurial orientation of SMEs in Labuan and its effects on performance. Working Paper. Faculty of Economics and Business. University of Malaysia http://ir.unimas.my/199/

BIS (2012). Business population estimates 2010 to 2012. https://www.gov.uk/government/statistics/bis-businesspopulation-estimates

Carson, D. (1990). Some exploratory models for assessing small firm's marketing performance (a qualitative approach). European Journal of Marketing, 24/1, 5-51.

Chaffee, EE. (1984). Three models of strategy. Academy of Management Review, 1855, 10(1), 89-98.

Chia, R, \& MacKay, B. (2007). Post-Processual Challenges for the Emerging Strategy-As-Practice Perspective: Discovering Strategy, in the Logic of Practice. Human Relations, 60(1), 217-242.

Cragg, PB, King, M. (1988). Organizational Characteristics and Small Firms' Performance Revisited. Enterprise Theory and Practice, 49-64.

Cronbach, LJ. (1951). Coefficient alpha and the internal structure of tests. Psychometrika, 16, 297-334

De Koning, AJ, Terrence, EB. (2001). The Impact of Entrepreneurial Orientation, Market Perceptions and Industry Munificence on Opportunity Alertness: A Longitudinal Study, Frontiers of Entrepreneurship Research, Babson College, Babson Park, Mass.

De la Viña, L, Lingelbach, D, \& Asel, P. (2005). What's Distinctive About Growth-Oriented Entrepreneurship in Developing Countries? Silicon Valley Review of Global Entrepreneurship Research, 1(2005), 92-102.

Franczak, J, Weinzimmer, L, \& Michel, E. (2009). An empirical examination of strategic orientation and SME performance. Small Business Institute National Proceedings, 33, No. 1 Winter.

Ghani, KDA, Nayan, S, Izaddin, S. A, Ghazali, SM, Shafie, LA. (2010). Critical internal and external factors that affect firms strategic planning. International Research Journal of Finance and Economics, Issue 51, 50-58.

Gibb, AA, \& Scott, M. (1985). Strategic awareness, personal commitment and the process of planning in the small business. Journal of Management Studies, 22(6), 597-631.

Gibbons PT, O'Connor T (2005). Influences on strategic planning processes among Irish SMEs. Journal of Small Business Management, 43(2). (http://www.questia.com/library/journal/1G1-13287076).

GOK. (2003). Economic Recovery Strategy For Wealth and Employment Creation 2003 - 2007. Nairobi: Government Printers.

Gomez GM (2008). Do micro-enterprises promote equity or growth? Evaluation report, Woorden Daad, Gorinchem, The Netherlands

Government of Kenya. (2012). Sessional paper No. 10 of 2012 On Kenya Vision 2030. Nairobi: Government Printers.

Grimsholm E, Poblete L (2010). Internal and external factors hampering SME growth. A qualitative case study of SMEs in Thailand. Thailand: Gotland University Press

Hajipour, B, Bagheri, M, \& Ghanavati, M. (2010). The Impact of Socio-Cultural Innovation and Brand Management on Financial Performance and Brand Performance of the Companies Listed in Tehran Stock Exchange. Research Journal of International Studies, 15, 55-68. 
Hansen, GS, \& Wernerfelt, B. (2007). Determinants of Firm Performance: The Relative Importance of Economic and Organizational Factors. Strategic Management Journal, 10(5), 399-411. Available on http://www.jstor.org.

Hill, CWL, \& Gareth, RJ. (2008). Strategic management: an integrated approach (8th ed.). USA: Houghton Mifflin Co.

Hill, CWL, \& Gareth, RJ. (2012a). Essentials of strategic management. USA: Cengage Learning.

Hill, CWL, \& Gareth, RJ. (2012b). Essentials of strategic management (3rd ed.). Boston: Cengage Learning.

Hofer, W. C. \& Schendel, D. (1978). Strategy Formulation: Analytical Concepts, West Pub.Company,Amazon.com

Huang X (2011). Strategic decision making in Chinese SMEs. Emerald Group Publishing Available: http://www. emeraldinsight.com/case_studies.htm

Irungu, IK. (2011). Adoption of formal strategic management practices among the small and medium enterprises within Mombasa County in Kenya. http://erepository.uonbi.ac.ke:8080/handle/123456789/4374

Jiang Q (2009). Strategic management in East Asia SMEs: the case study of SMEs in China and Indonesia (unpublished Master's thesis in Business Administration, Jönköping University, June 2009)

Johnson, G, Whittington, R, \& Scholes, K. (2011). Exploring corporate strategy (9th ed.). England: Prentice Hall.

Karlan, D, \& Valdivia, M. (2011). Teaching Entrepreneurship: Impact Of Business Training On Microfinance Clients and Institutions (May 2011). Review of Economics and Statistics, 93(2), 510-527.

Kiruja M (2011). Strategic management practices in small and medium enterprises at Kariobangi Light Industries, Nairobi. http://erepository.uonbi.ac.ke:8080/xmlui/handle/123456789/14462

Kraus, S, Reiche, SB, Reschke, CH, \& (2007). Implications of strategic planning in SMEs for international entrepreneurship research and practice. In M Terziovski (Ed.), Energizing management through innovation and entrepreneurship: European research and practice (pp. 110-127). London: Routledge.

Leitner, KH. (2007). Energizing management through innovation and entrepreneurship: European research and practice. London, pp. 110-127: Routledge.

Lumpkin, GT, \& Dess, GG. (2006). The effect of simplicity on the strategy-performance relationship: a note. Journal of Management Studies, 43(7), 1583-1604.

Martínez, JA. (2009). Entrepreneurship policies and new business performance and growth: an Empirical analysis based on manufacturing industries environment and planning. Government and Policy, 27(2), 195-215.

Mead D (1999). Energizing management through innovation and entrepreneurship: European research and practice. In K. King and S. McGrath (Ed.), Enterprise in Africa between poverty and growth (pp. 110-127). London: Intermediate Technology Group Publishing.

Menzel, D, \& Günther, L. (2012). Formal and informal strategizing in a SME. Proceedings of the International Symposium on Innovation Methods and Innovation Management, Chemnitz, Germany, 29-30 March, 2012.

Metts, GA. (2011). Decision making and strategy development in SMEs: an empirical investigation into the role of adaptation. International Review of Business Research Papers, 7(6), 65-83.

Mintzberg, H, Ahlstrand, B, \& Lampel, J. (1998). Strategy safari a guided tour through the wilds of strategic management. New York: Free Press.

Mintzberg H. \& Waters JA. (1985). Of strategies, deliberate and emergent. Strategic Management Journal, 6(3), 257-272. http://www.jstor.org/stable/2486186

Minzberg, H. (1978). Patterns in strategy formulation. Management Science, 24(9), 935-948.

Monsicha, I, \& Nantana, O. (2011). Effects of organizational characteristics on performance of travel agencies in Thailand. International Academy of Business and Economics, 11(3), 65-91.

Moog, P, Mirabella, D, \& Schlepphorst, S. (2011). Owner orientations and strategies and their impact on family business. International Journal of Entrepreneurship and Innovation Management, 13(1), 95-112.

Morrison, J. (2006). International business environment: global and local marketplaces in a changing world (2nd ed.) New York: Palgrave MacMillan.

Mugenda OM, Mugenda AG (2013). Research methods, ACTS, Nairobi

Mutua, KJ. (2013). Operational challenges in the growth of small and medium enterprises in kisumu county, Kenya, University of Nairobi Digital Repository: http://hdl.handle.net/11295/63363

Nagel, A. (1984). Organizing for strategic management. Long Range Planning, 17(5), 71-78.

Obaidullah, AZM, \& Alam, MS. (2011). Effect of Entrepreneur and Firm Characteristics on the Business Success of Small and Medium Enterprises (SMEs) in Bangladesh. International Journal of Business and Management, 6(3), 289-299.

Pearce, JA, II, \& Robinson, RB, Jr. (2011). Strategic management: strategy formulation, implementation, and control (12th ed.). Chicago, IL: R. D. Irwin, Inc.

Porter, EM. (1985). Competitive advantage: creating and sustaining superior performance. New York: Free Press.

Quinn, J. B. (1980). Strategies for change: logical incrementalism. Burr Ridge: Richard D, Irwin.

Qureshi, MH. (2012). Factors Affecting Small-Business Performance In Punjab-Pakistan: Gender Based Analysis. Interdisciplinary Journal Of Contemporary Research In Business, 4(2).

Republic of Kenya. (2007). Kenya vision 2030. Nairobi: Government Printers.

Sarwoko, E., Surachman, A., \& Hadiwidjojo, D. (2013). Entrepreneurial characteristics and competency as determinants of business performance in SMES. IOSR Journal of Business and Management (IOSR-JBM) e-ISSN: 2278-487X, 7(3), 31-38.

Siow, H, \& Teng, S. (2011). Government Policy and Critical Success Factors of Small Businesses in Singapore. Newcastle: Cambridge Scholars Publishing.

Tenai, JK, Bitok, JK, Cheruiyot, TK, \& Maru, LC. (2009). Moderating Variables on SME's Strategies and Competitiveness for International Trade: A Survey of Horticultural Traders in Urban and Peri-Urban Areas of Kenya. International Business and Economics Research Journal, 8(12), 105-114. The Clute Institute for Academic Research, U.S.A. http://journals.cluteonline.com.

Tuli, F. (2012). The basis of distinction between qualitative and quantitative research in social science: reflection on ontological, epistemological and methodological perspectives. Riverside County: Sage.

Verreynne, M. (2006). Strategy-making processes and firm performance in small firms. Journal of Management \& Organization, 12, 209-222.

Verreynne, M, Meyer, D (2007). Modeling the Role of Intrapreneurial Strategy-Making in Small Firm Performance. In GT Lumpkin, Jerome A, Katz (Eds.), Entrepreneurial Strategic Processes (Advances in Entrepreneurship, Firm Emergence and Growth, Volume 10) (pp.103-130). Emerald Group Publishing Limited. 
Wang, C, \& Walker, EA. (2012). Explaining the lack of strategic planning in SMEs: the importance of owner motivation. Janice Redmond International Journal of Organizational Behavior, 12(1), 1-16.

Yamane, T. (1967). Elementary sampling theory. USA: Prentice-Hall, University of Michigan.

Youth Enterprise Development Fund. (2012). Status Report (2007-2012). Nairobi: Government Press.

Zainol FA, Ayadurai S (2011). Entrepreneurial orientation and firm performance: the role of personality traits in Malay family firms in Malaysia. International Journal of Business and Social Science, 2(1)

\section{Submit your manuscript to a SpringerOpen ${ }^{\circ}$ journal and benefit from:}

- Convenient online submission

- Rigorous peer review

- Immediate publication on acceptance

- Open access: articles freely available online

- High visibility within the field

- Retaining the copyright to your article

Submit your next manuscript at $>$ springeropen.com 